\title{
Clubhouses Response to COVID-19: Member Challenges and Clubhouse Adaptations
}

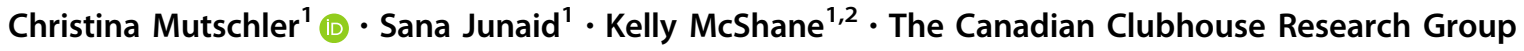

Received: 1 October 2020 / Accepted: 27 November 2020/Published online: 2 January 2021

(C) The Author(s), under exclusive licence to Springer Science+Business Media, LLC part of Springer Nature 2021

\begin{abstract}
Clubhouses have been found to improve a variety of psychosocial outcomes for individuals with mental health concerns. Due to the barriers encountered during COVID-19, Clubhouses adapted their programming to meet member's needs. The purpose of the present study was to document and synthesize Clubhouse member's needs and Clubhouse adaptations during COVID-19. Clubhouse members, staff, and directors $(n=29)$ from five accredited Clubhouses across Canada participated in interviews about their experiences within Clubhouses during the pandemic. Interview notes were analyzed using thematic analysis through an iterative process until consensus occurred. The results indicated a number of challenges that Clubhouse members experienced including increased mental health symptoms, isolation and loneliness, and difficulty accessing services. Clubhouse adaptations included increased communication, expansion of the meal program, and sustained program delivery through technology. The results suggest that COVID-19 has provided an opportunity for Clubhouses and other community-based organizations to innovate to meet their member's needs.
\end{abstract}

Keywords Clubhouse $\cdot$ Psychosocial rehabilitation $\cdot$ Adaptation $\cdot$ COVID-19

\section{Introduction}

The Clubhouse model is a type of psychosocial rehabilitation that provides individuals with mental health concerns opportunities to engage within their communities through a variety of programs and services (ICCD 2015). Programs offered within the Clubhouse reflect the "workordered day", which involves operations of the Clubhouse (e.g., clerical work, food preparation, marketing); transitional and supported employment opportunities; as well as a number of social activities that are organized by the Clubhouse. The recent global pandemic caused by COVID19 has interrupted the service provision of Clubhouses

The Canadian Clubhouse Research Group contains all directors, staff, and members from the following Clubhouses: Fitzroy Centre, Notre Dame Place, Oak Centre, Potential Place, and Progress Place.

Christina Mutschler

Christina.mutschler@ryerson.ca

1 Department of Psychology, Ryerson University, 350 Victoria Street, Toronto, ON M5B 2K3, Canada

2 School of Health Services Management, Ryerson University, Toronto, Canada around the world, leading to many Clubhouses having to rapidly adapt their programming to meet the needs of their members. Documenting and sharing lessons learned can provide a template for innovation for other communitybased mental health organizations during COVID-19.

\section{Clubhouse Model of Psychosocial Rehabilitation}

The efficacy of Clubhouse participation on various outcomes has been well researched. A recent systematic review indicates that participation in the Clubhouse decreases mental health symptoms, hospital visits, and increases overall well-being (McKay et al. 2018). Further, studies have indicated that members work more hours and attain a higher wage than individuals involved in other services (Schonebaum et al. 2006). Additionally, members have been found to show improvements in schizophrenia symptoms (Tsang et al. 2010), relationships (Mutschler et al. 2018), access to social support (Biegel et al. 2013), greater quality of life and self-esteem (Gold et al. 2016) and less feelings of stigma (Jung and Kim 2012).

Research has found that individuals with severe mental illness have smaller or less satisfactory social networks (Corrigan and Phelan 2004). Therefore, they often suffer 
from social isolation and do not have enough resources to depend on during times of need. Strengthening the relationships and social networks of individuals with severe mental health issues is a goal of all Clubhouses. Clubhouses provide a community for members that includes acceptance, a sense of belonging, and reduction of stigma, which in turn, promotes the development of meaningful relationships (Mutschler et al. 2018).

\section{Mental Health Impact of COVID-19}

The global pandemic of COVID-19 has had a significant impact on psychosocial outcomes due to increased isolation, financial unpredictability, and overall stress. Recent data from the COVID-19 pandemic suggests that Canadians reported increases in anxiety from 5 to $20 \%$ and increases in depression from 4 to $10 \%$ (Martin and Cooper 2020). Further, the report indicates that $33 \%$ of participants had limited access to mental health supports and $27 \%$ reported a decreased quality in supports (Martin and Cooper 2020). Research has found that those with preexisting mental health concerns are particularly vulnerable during a pandemic due to barriers in accessing healthcare, such as discrimination, access to information, and service closure (Yao et al. 2020). In addition, the added stress of COVID-19 can aggravate pre-existing conditions due to higher stress, which has been found to be especially salient for individuals with symptoms of psychosis (Kozloff et al. 2020). This is of note as many Clubhouse members identify as individuals with a severe mental illness, including psychosis-spectrum disorders (Raeburn et al. 2013).

\section{Purpose}

The recent global pandemic caused by COVID-19 has interrupted the provision of in-person services typically offered by Clubhouses, leading to the decision to either close their centre or to rapidly adapt their programming to meet the needs of their members. In Canada, many Clubhouses decided to adapt their programming and introduce new innovations in Clubhouse services to support their members. To date, no research has been done on the experiences of Clubhouses during the COVID-19 pandemic, including member challenges, the implementation of innovations, and successes or challenges. The Mental Health Commission of Canada has recommended that services evaluate interventions during COVID-19 and quickly share the lessons learned in order to decrease COVID-19-related mental health concerns (Mental Health Commission of Canada 2020).

The purpose of the present study was to document and synthesize the experiences of five accredited Clubhouses across Canada during the COVID-19 pandemic in order to create an overview of best practices. The research questions included: What are the challenges of members during COVID-19? How have Clubhouses adapted to meet members' needs? What were the successes and challenges of the adaptations? The results can be used by other Clubhouses as a guide of adapting service provision as they navigate the pandemic and the future of in-person services.

\section{Method}

\section{Sample}

The present study employed a qualitative case study design that included five accredited Clubhouses across Canada. These Clubhouses represented Alberta $(n=1)$, Nova Scotia $(n=1)$, Ontario $(n=2)$, and Prince Edward Island $(\mathrm{PEI} ; \mathrm{n}=1)$. Interviews were conducted with key stakeholders from each of these sites including staff, members, and directors. Stakeholders that were not able to attend an interview were offered the option to complete an openended interview via an online questionnaire. The sample of individuals who participated in the interviews consisted of a total of 22 participants, of which 4 identified as members. Further, 7 individuals participated in the online survey, with one of them being a Clubhouse member. The participants represented all five Clubhouses, with the range of interviewees from each site being 4 to 7 . Administrative data was also collected from sites, including rates of member participation in various implemented programs.

\section{Interview Guide}

The semi-structured interview guide was derived from the integrated Promoting Action on Research Implementation in Health Services (i-PARIHS) framework (Harvey and Kitson 2016) and included themes relevant to the research questions, including problem identification, characteristics of innovation, appraising evidence, mechanisms for embedding change, and networking. The interviews asked participants what programs were adapted; what challenges occurred after the adaptations, as well as what parts of the programs were adapted effectively. Participants were then asked to describe the process of program adaptation, which included recognizing member needs, innovation, and implementing the adapted programs. Finally, participants described both the challenges and successes of the newly adapted programming.

\section{Procedure}

Staff at the various Clubhouses were informed about the study by their Executive Directors. Members who had been a part of the implementation process (e.g., consultation, 
planning, executing) were also invited to participate in the study. Potential participants contacted the primary researcher to participate in the study and gave informed consent to complete the interview. The interviews were approximately $45 \mathrm{~min}$ in length and were conducted over Zoom. Detailed notes were taken as close to the spoken word as possible by another member of the research team during the interview. Additional stakeholders who were unable to schedule an interview due to time restraints were provided the option to fill out a Google Form containing the interview questions with long answer text boxes. Administrative data, including participation rates across programs, was provided by all Clubhouses.

\section{Analysis}

The data was analyzed using thematic analysis in order to identify themes across Clubhouse sites (Braun and Clarke 2006). The authors independently reviewed and coded transcripts and then met regularly to discuss codes and create larger themes. Consensus of the themes and organization of themes was an iterative process between original transcripts, codes, and themes. Data was collected and analyzed until saturation was evident. Themes were further refined after feedback from the Clubhouses, including staff and directors. The research was approved by the Health Research Ethics Board of Alberta.

\section{Results}

There were four major themes that emerged from the data. These included member challenges, Clubhouse adaptations, challenges with adaptations, and Clubhouse being forever changed. These themes included various subthemes that will be further discussed below and are described in detail in Table 1.

\section{Theme 1: Member Challenges}

The first theme addressed difficulties members faced during the pandemic, which included four subthemes. Participants noted that members identified increased mental health symptoms due to COVID-19; increased isolation and loneliness; difficulty accessing services; and disruption of routine, including the engagement in the work-ordered day.

\section{COVID-19 Leading to Increased Mental Health Symptoms}

Participants described that due to the uncertainty surrounding COVID-19, members experienced increases in mental health symptoms, including anxiety and depression.
Members who had anxiety and depression symptoms prior to COVID-19 often experienced increases in these symptoms; while those who did not have these symptoms previously began to experience them. This was substantiated by participants who noted:

I think what has compounded for our members, is issues around their mental health, if you were already anxious, increased anxiety, already depressed, increased depression, and if you didn't exhibit these symptoms prior to COVID-19, we have seen members that are increasingly showing anxiety and depression because of the isolation" (Participant 15). Members also described feelings of anxiety and fear surrounding the pandemic. One member reported: "I am very afraid to get the virus... I may not be back at the Clubhouse until there is a vaccine... I am really afraid of what is going to happen to me if I have to stay at home for another year" (Participant 10b).

These quotes illustrate that increased mental health symptoms were a major challenge that participants faced, and this challenge existed irrespective of mental health symptoms prior to the pandemic. The uncertainty and fear surrounding the pandemic led many members to feel anxious and depressed.

\section{Isolation and Loneliness}

The second subtheme that emerged from the research data was feelings of isolation and loneliness during the pandemic. Participants discussed that members reported increased feelings of loneliness due to being required to socially distance or isolate themselves. This often led to mental health problems for members who used the Clubhouse for social connection and were now required to isolate. A member discussed the difficulties she faced surrounding isolation: "I have so much trouble with isolation and now it's almost like I am forced to do that, almost making [me] regret that time [I] was isolating" (Participant 3).

Other participants expressed similar sentiments around isolation, reporting that members often faced increased mental health issues when they were forced to isolation themselves. Participant 11a and Participant $11 \mathrm{~b}$ explained that:

There was a lot of fear as to what was happening, there was definitely increased anxiety. The whole idea of the Clubhouse model being a community centre or hub is based on the model that it is important for people not to isolate. Isolation can have huge effects on people's mental health- increased anxiety and depression. 
Table 1 Description of themes

\begin{tabular}{lll}
\hline Theme & Codes & Description \\
\hline $\begin{array}{l}\text { Member } \\
\text { challenges }\end{array}$ & $\begin{array}{l}\text { COVID-19 leading to } \\
\text { increased mental health } \\
\text { symptoms }\end{array}$ & $\begin{array}{l}\text { Participants described that due to the uncertainty } \\
\text { surrounding COVID-19, members experienced } \\
\text { increases in mental health symptoms, including } \\
\text { anxiety and depression. Members who had } \\
\text { anxiety and depression symptoms pre-COVID- } \\
\end{array}$ \\
$\begin{array}{l}19 \text { often experienced increases in these } \\
\text { symptoms; while those who did not have these } \\
\text { symptoms previously began to experience } \\
\text { them }\end{array}$
\end{tabular}

Isolation/loneliness

Access to services (food transportation, medication, mental health services)
Participants discussed that members reported increased feelings of loneliness due to them being required to socially distance/ isolate themselves. This often led to mental health problems for members who used the clubhouse for social connection and were now required to isolate

Participants reported a multitude of service disruptions that members faced including difficulty in affording food when many organizations shut down. In addition, accessing transportation to obtain groceries and other needs such as medications and health appointments also proved to be a challenge for members due to disruptions in members transportation systems

\section{Sample quotes}

I think what has compounded for our members, is that issues around their multiple health, if you were already anxious, increased anxiety, already depressed, increased depression, and if you didn't exhibit these symptoms prior to COVID- 19, we have seen members that are increasingly showing anxiety and depression because of the isolation

Very afraid to get the virus; may not be back at the clubhouse until there is a vaccine... I am really afraid of what is going to happen to me if I have to stay at home for another year

I think, they were just experiencing an enhanced version of what most people were experiencing, generally anxiety is higher given the pandemic, but without members even when there is not a pandemic they have trouble looking at that longer term perspective and watching news all the time. At first there was a lot of anxiety around it, and after the physical isolation they had to undergo

I have so much trouble with isolation and now it's almost like I am forced to do that, almost making her regret that time she was isolating

There was a lot of fear as to what was happening, there was definitely increased anxiety. The whole idea of the clubhouse model being a community centre or hub is based on the model that it is important for people not to isolate. Isolation can have huge effects on people's mental health. I think that was something everyone was quite concerned about. We know what that is going to end up looking like. Increased anxiety and depression

Definitely more anxiety, more concern for their own well being of being isolated, even sadness of just missing the people that they would typically lean on for companionship

The other thing was food, we have tons of members that get daily lunches, and we were going to food bank every week and stocking up on tons of food, and members could come in every week and take home bags of food, that was something we were concerned about people on strict budgets who can't afford to get food

Food insecurity was a thing, a lot of difficulty with working around the public health and safety measures. They have to change up their routine, how they are going to get to the bank or their medications. Groceries. All those things. Making sure they have their medications was the most important and helping finding employment was lower down. We started with the things members were saying, how to get groceries, keep appointments, that they know they can call people 
Table 1 (continued)

\begin{tabular}{|c|c|c|c|}
\hline Theme & Codes & Description & Sample quotes \\
\hline
\end{tabular}

Disruption of routine/ engagement in workordered day; loss of identity

\section{Clubhouse Expansion of meal adaptations programs}

Participants reported that members struggled when their daily routine was disrupted. Clubhouse added structure and regularity to members live's, providing companionship, support, and meals. When Clubhouse closed, members lost the structure that had been built into their lives through engaging in the clubhouse and work ordered day

The expansion of meal services involved delivery of meals, food baskets, and groceries to members houses. This expansion was in response to the members functional need of accessible food
Increased communication
The increased communication theme includes increased newsletter provision, outreach to members, and extended access to help lines by the clubhouse
Transportation has been an issue here so people who need groceries our bus system here in

Welland is really poor so people haven't been able to get out to get their groceries so that has been a struggle for people

People need to be getting out. I feel myself, that I get to come to work everyday. That adds structure to my life. And the clubhouse for a lot of members adds structure to their day too. So I think that if we don't have structure and we don't get outside, these are all things that the clubhouse model is based on. We are going to see some deterioration

I think the challenge in my eyes was they lost structure, so we have about 25-30 people that use clubhouse on a daily basis, that can go up and down, and we have people who spend $4 \mathrm{~h}$ a day with us, who come have lunch with us, ppl who need employment with us, so taking out meals, taking out support and taking out structure

The longer it goes on it is more difficult [for members] whose routine is so important for them. They are having a harder time. Those members who live farther away, those people can only access us remotely

Delivering lunches everyday with hampers, preparing and delivering those, monday to friday, and hampers were delivered only on fridays

The food is now being produced by the staff in the clubhouse. So we did one meal a day, two meals on friday. There is a whole group of staff that do that and then another group that delivers the meal. Members come to the clubhouse everyday to pick up the meal

Some of the benefits is that the food is free- so that is helping us financially. Also it gives routine. I go at the same time everyday, I get to see [staff member], and it is the highlight of my day. So grocery shopping is a difficult thing for me due to physical health, so getting the food is helpful. I am talking to other members who are getting their food. I have become friends with a few that I haven't been friends with before. We social distance and just talk to each other

Purchasing groceries on a low income can be very difficult, which is why we have meals here. It makes things easier for people

We do have one supportive housing, we delivered meals to them throughout the whole pandemic so we were able to do that for them so we still did lunch and supper for them

We used to do newsletter once a month, now we're doing it every 2 weeks, we are trying to get others involved but it is hard, we included exercises, always what's going with covid, and 
Table 1 (continued)

\begin{tabular}{|c|c|c|c|}
\hline Theme & Codes & Description & Sample quotes \\
\hline
\end{tabular}

colouring and activities that people could engage in with the newsletter

I designed a little daily newsletter, here's how you can stay connected to clubhouse, here is

what is going on in the community and here is some mental health supports, and sending that out at the same time everyday and try to keep people motivated, and if people are struggling and they are looking for something to do and be involved in, my goal has been to help that a long a little bit. People like the daily, I was worried that people would get tired after a while, but people are still clicking on it, it's helpful when people are stuck at home

When we started making calls I told staff ask members when they wanna be called and when they were available and if staff wanted to take off a couple hours in the morning they could do the calls at night, we were trying to figure out when they were loneliness, and staff started making calls everyday, at first they were short but then people started looking forward to calls

Consistency of reaching out with members to make the effort. I think that was the most important thing. Letting them know we are still available to them for help. Calling them and checking in and telling us about their day is so important. It was vital that we let them know that our relationships are going to continue even if the centre is closed

And then our warm line, where as they were $8 \mathrm{pm}$-midnight, it got expanded from 12 to 12 to help meet that need and is on the toronto website recommending the warm line to all of the city which is a big deal, promotion to get people calling in

Sustained Program Delivery Through Technology
Clubhouses used various technology resources to fill gaps within their services including Facebook, Zoom, and Slack. Clubhouses used these services to increase social connection through social recreation, increase participation in the work ordered day, and promote wellness through the health and wellness program
Facebook was an easy way to touch base with people because some people don't answer phones and people would be able to reach out whenever they wanted to reachout. I know with social rec some people did trivia on facebook, that went really well because you could chat back and forth... a good way to keep social connection even though you weren't right next to each other

The other interaction is the social interaction, being able to connect with fellow members and seeing people. That is when we started doing virtual. All of this we did the first week we closed. Then we decided what the content would be of the activities. Like health and wellness, we knew people would be at home by themselves. How to make the space you are living in ok. We started meetings for people with addictions. We did lots of education really early on, learning Spanish and French

The one thing that is still challenging is getting people involved in the work order day, so that was tough to see... how to get people involved 
Table 1 (continued)

\begin{tabular}{|c|c|c|c|}
\hline Theme & Codes & Description & Sample quotes \\
\hline
\end{tabular}

in the work order day, something that I picked up, the clubhouse in New York put up this whole template, and they said they were using slack to get people involved in work order day. So I started that with a couple of members, and

people really liked it, and as people got more and more used to it, it has become integral into keeping people involved in work, especially for the marketing unit

We started to do social rec virtually, initially we started with facebook live, facebook is more familiar than some of the other ones bc of our older population, we were doing virtual scavenger hunts. We did add zoom later as well and have started to do some social rec through zoom so staff could help facilitate it as well. We also started weekly unit meetings, 4 unit meetings at our clubhouse, and first it was just check in to get everyone on and how they are doing, and then like online job resources, and then just talking about cerb and getting on CERB

Challenges Technology to adaptations
One challenge that was mentioned by every clubhouse was access to technology. Clubhouses noted that some members did not have access to the internet or devices (smartphone/tablet) which limited their ability to stay connected with the clubhouse. On the other hand, members who did have access often struggled with using the various applications such as Zoom or Slack, due to the learning curve involved with the new technology
Everybody reacts a bit differently, some people that were more tech savvy jump at the chance to be involved at home, members we hadn't seen involved in the clubhouse for a while came out of the woodwork to be involved with zoom, slack, because it fit really well for them. They like working from home, submitting tasks and staying connected, the people that were not tech savvy, it hit them a lot harder and it was a lot harder to stay connected to them. Members that aren't big phone people, it was tough to stay in touch with them. A lot of young adults were fine, we stay connected with them, biweekly zoom calls, and they did okay, because for a lot of young adults, it is very normal to be connected remotely its easier, they often have a lot of friends they saty into contact with texting, apps, so they were able to more easily adjust, but the older population struggled more

Slack is good for what it is but you have to be tech savvy to wrap your head around what it is and some members aren't as tech savvy and we are trickling people into slack as needs pop up

One drawback about zoom is that some members don't have access to a computer, some don't know how to navigate media platforms. For people who are tech savvy it's no problem, but for other members it was more of a challenge. We didn't have as good of an uptake as in person, less members were joining the zoom meetings. It was more of a challenge than we would've liked to see. We are hoping to try and teach more social media platforms in the clubhouse so that more members can click into zoom or teams 
Table 1 (continued)

\begin{tabular}{|c|c|c|c|}
\hline Theme & Codes & Description & Sample quotes \\
\hline
\end{tabular}

Re-opening challenges
Participants discussed challenges with reopening the clubhouse and following guidelines put forth by various public health organizations. These guidelines required social distancing, safety protocols, and limited number of members onsite. These barriers led to prioritizing members who were having the

most challenges, limiting the time members can stay at the clubhouse, and maintaining physical distance during side by side work. These changes are all shifts from the usual clubhouse standards
Now that we are reopen we have to go with guidelines of PEI public health and safety and we are only allowed so many members each time and each area and members can go from one area to the other, they are structured from one area to the other, and normally everything is totally open and everyone is working

together at all, but people are adapting now that we have had the week and 2 weeks under our belt and thinks will gradually change as public health gives us new directions. Some members that would come everyday, and stay all day only get mornings which is really hard to explain and for members to accept sometimes

I'm not sure, I feel this is what I am struggling with going back to club house and we opened last week and meeting with everyone individual and making sure everyone is okay and they don't need any media services or anything, just how the clubhouse is organized now is diff and I am more worried about following the model now than when we were closed, for ex the side by side and having to maintain a 6 foot diff and not having to maintain as many ppl in diff areas of the building, and I think we are going to have a harder time sticking with the mode now then when we were doing the virtual stuff

If I am having a convo online with somebody, and it becomes side by side work and we are collaborating work, and that will still be able to happen but I can see some issues like if people need help with technology it's going to be a whole process, well you need to move away from workstation and sanitize, and then I can go in, we didn't really get that when we were virtual but I do feel like we were able to work together and support one another, and most people would say employment standards were diff, and have suffered and will continue to suffer for while, but we were still able to provide maintenance for people who were employed, and relationships was a standard that we were able to maintain, so overall I guess we were able to maintain the model given the circumstances

So just going back to when we were opening and having members back into clubhouse some of the conversation that we had, our conversation was about members who we had been conversing with and decompensating, and collaborating with their social supports along with members, and these were members we invited back into clubhouse first and made sure they could get help, and talked to their health care workers and work with support workers and get back on par with their wellness 
Table 1 (continued)

\begin{tabular}{|c|c|c|}
\hline Theme & Codes & Description \\
\hline $\begin{array}{l}\text { Forever } \\
\text { changed }\end{array}$ & & $\begin{array}{l}\text { The changes that have been made due to the } \\
\text { pandemic have left a permanent mark on all } \\
\text { Clubhouses, as it is unclear as to whether } \\
\text { clubhouses will ever be able to exist as they } \\
\text { once did. The need for alternative methods of } \\
\text { program delivery created new ways to engage } \\
\text { members whether that was through virtual } \\
\text { programming, an increased focus on health and } \\
\text { wellness, alternative ways of food delivery or } \\
\text { increased reach out. Many clubhouses reported }\end{array}$ \\
\hline & & $\begin{array}{l}\text { that these changes would be permanent even as } \\
\text { clubhouses began to reopen as a new and } \\
\text { innovative way to engage members who cannot } \\
\text { come into clubhouse }\end{array}$ \\
\hline
\end{tabular}

Sample quotes

We have been able to reach people we haven't before. We are just starting to put together our reopening plans; we are pretty sure we are going to be running parallel services for a while. Even if we are opening up the clubhouse partially it will be on a different scale, with in person and zoom. I think it is going to really draw on our resources, because we are going to have to keep all these different programs at once. I think we will

see more membership partnership in the meetings. Members will help other members with Zoom. Although it is more work, there will be more people to help with these

I don't think zoom is going away permanently, since we reopened, we are doing unit meetings on zoom, and once we reopen, we will probably stop doing unit meetings on zoom. It is going to be a long time for people that are vulnerable, that probably won't be able to come out until stage 3, which won't be till a vaccination, so we will want to keep the zoom meetings at least for the rest of the year. I think they will become a part of their new norm, because they are very popular, because if people can't make it to clubhouse they can attend and be involved from home

I think switching our health and wellness meeting to a virtual one actually made it better, when we had it in person it was not ever very well attended, so during COVID they have been well attended and interactive and I think that has been a positive

We're seeing members getting involved in things they typically wouldn't; or meeting people they wouldn't have before. We are a pretty big clubhouse, that means there could be a lot of people that you don't get to meet. So I think that part has been an added bonus. You go into a meeting and see someone you haven't met. There are opportunities that you haven't been involved in before. Health and wellness activities- we have more people than we ever have. Because they are at home, it allows them the opportunity to take part in things. Like our yoga, sit and get fit classes, health and wellness. So I think when we do open back up, those people might stay connected with those who they met online and stay connected with activities they took part in
Participants also reported feeling of loneliness during the time they were required to socially distance themselves, as opportunities for social connection became limited. Participant 5 reports this challenge:
"[There is] concern for their own well-being of being isolated, even sadness of just missing the people that they would typically lean on for companionship". 


\section{Access to Services}

The third challenge that members reported was accessing services for their functional needs. Participants reported a multitude of service disruptions that members faced. When food banks and other organizations shut down this limited access to food and mental health services. In addition, accessing transportation to obtain groceries and other needs such as medications and health appointments was also a challenge for members due to disruptions in members transportation systems. Participant 18 discusses many of the service disruptions that members faced:

Food insecurity was a thing, a lot of difficulty with working around the public health and safety measures. How they are going to get to the bank or their medications? Groceries. All those things.

Limited access to transportation due to disruptions in services was also challenging, limiting opportunities to be able to get to and from essential services that members required. Participant 6 reported,

Transportation has been an issue here... our bus system here is really poor... so people haven't been able to get out to get their groceries. That has been a struggle for people.

\section{Disruption of Routine}

The final and fourth challenge that members faced when Clubhouses closed was disruption of their daily routines. Participants reported that members struggled when their daily routine was disrupted. Clubhouse added structure and regularity for members, providing companionship, support, and meals. When Clubhouses closed, members lost the structure that had been built into their lives through engaging in the Clubhouse and work ordered day. Participant $11 \mathrm{~b}$ discussed the need for structure that had become disrupted:

People need to be getting out. The Clubhouse for a lot of members adds structure to their day. So, I think that if we don't have structure and we don't get outside, these are all things that the Clubhouse model is based on. We are going to see some deterioration.

The loss of structure was repeatedly discussed as a member challenge. Participants were no longer able to come into the Clubhouse, participate in chores and work, and generate a sense of routine and consistency in their lives. Participant 6 elaborates on this:

I think the challenge in my eyes was they lost structure, so we have about 25-30 people that use
Clubhouse on a daily basis, and we have people who spend four hours a day with us, who come have lunch with us, people who need employment with us, so taking out meals, taking out support and taking out structure.

\section{Theme 2: Clubhouse Adaptations}

The second theme examined the adaptations that Clubhouses implemented over the course of the pandemic, including increased communication, expansion of the meal program, and sustained program delivery through technology.

\section{Increased Communication}

One Clubhouse adaptation that was made was increasing the amount of communication Clubhouse staff had with members. This included increased newsletter provision, outreach to members, and extended access to help lines by the Clubhouse. All of these services were previously offered by the Clubhouses but were increased significantly during the pandemic. Participant 13 discusses the adaptations made to the monthly newsletters:

We used to do a newsletter once a month, now we're doing it every 2 weeks, we included exercises, always what's going with COVID, and colouring and activities that people could engage in with the newsletter.

Other adaptations included increasing the amount of outreach to members. This involved a significant increase in calls to members, with one Clubhouse reporting a $425 \%$ increase in calls and a $100 \%$ increase in call length from 2019. Across all Clubhouses, 10,663 calls were made over the months of April and May 2020. Increasing outreach was done consistently across every Clubhouse and is discussed by Participant 9:

When we started making calls, I told staff to ask members when they wanna be called and when they were available and if staff wanted to take off a couple hours in the morning, they could do the calls at night. We were trying to figure out when they were lonely, and staff started making calls every day.

Participant 18 stressed the importance of remaining in communication with members:

Consistency of reaching out with members to make the effort. I think that was the most important thing. Letting them know we are still available to them for help. Calling them and checking in and telling us about their day is so important. It was vital that we let 
them know that our relationships are going to continue even if the centre is closed.

\section{Expansion of Meal Program}

In response to the food challenges that were consistently reported across all Clubhouses, existing meal programs were expanded. The expansion of meal services involved delivery of meals, food baskets, and groceries to members houses. Over the first 2 months that the Clubhouses were closed, approximately 7224 meals and 242 food hampers were provided across the five Clubhouses. This was done in order to fulfill members functional needs for accessible food. One staff member reflected:

The food is now being produced by the staff in the Clubhouse. So, we did one meal a day, two meals on Friday. There is a whole group of staff that do that and then another group that delivers the meal. Members come to the Clubhouse every day to pick up the meal. (Participant 10a).

Members who could pick up their food from the Clubhouse also discussed that the food pick up provided the opportunity to engage in social connection as well as lifted some of their financial burdens. Participant 10b, a Clubhouse member, expanded on this:

Some of the benefits is that the food is free- so that is helping us financially. Also, it gives routine. I go at the same time every day, I get to see [Clubhouse staff member], and it is the highlight of my day. So, grocery shopping is a difficult thing for me due to physical health, so getting the food is helpful. I am talking to other members who are getting their food. I have become friends with a few that I haven't been friends with before. We social distance and just talk to each other.

\section{Sustained Program Delivery through Technology}

Participants reported that Clubhouses used various technological resources to fill the gaps within their services including Facebook, Zoom, and Slack. Typical Clubhouse programming that was offered via video calls included unit meetings, health and wellness sessions, social recreation, community meetings, and housing meetings. Across the months of April and May, attendance to video meetings across the five Clubhouses was 2289 members. Participant 16 discussed the use of Facebook to deliver programming and stay connected to members:

Facebook was an easy way to touch base with people because some people don't answer phones and people would be able to reach out whenever they wanted to reach out. I know with social recreation, some people did trivia on Facebook, that went really well because you could chat back and forth... a good way to keep social connection even though you weren't right next to each other.

Members noted that having meetings over Zoom was a way that they could stay connected with the Clubhouse and lessen their feelings of loneliness and isolation. One member noted:

Currently we have unit meetings over Zoom. It gives the members the opportunity to ask questions and find out what is going on. The staff is encouraging people to call if they have problems or issues. We are still a community even if we can't come together physically. We are not social distancing, we are physically distancing, we are still a social community (Participant 10b).

Participant 7 discussed another program that was offered through Clubhouse that engaged members in the work ordered day:

The one thing that is still challenging is getting people involved in the work order day, so that was tough to see... something that I picked up was Slack... to get people involved in the work order day. So, I started that with a couple of members, and people really liked it. As people got more and more used to it, it has become integral to keeping people involved in work.

\section{Theme 3: Challenges to Adaptations}

When Clubhouses began to adapt their programming in response to the pandemic, they inevitably faced some difficulties when implementing new changes. The two main challenges that Clubhouse faced with respect to their adaptations were found in the use of technology as well as challenges in reopening the Clubhouse.

\section{Technology}

Access to technology was a challenge that was mentioned by every Clubhouse. Clubhouses noted that some members did not have access to the internet or devices (e.g., smartphone/tablet) which limited their ability to stay connected with the Clubhouse. On the other hand, members who did have access often struggled with using the various applications such as Zoom or Slack, due to the learning curve involved with the new technology. Participant 18 discussed the technology barriers that many members 
reported which ultimately impaired participation in virtual programming:

One drawback about Zoom is that some members don't have access to a computer, some don't know how to navigate media platforms. For people who are tech savvy it's no problem, but for other members it was more of a challenge. We are hoping to try and teach more social media platforms in the Clubhouse so that more members can click into Zoom or Teams.

Ultimately, those who were more familiar with technology had an easier time accessing virtual platforms and participating in virtual programming. Those less familiar with technology struggled with the virtual programming and were not able to participate in programming to the same extent. This is expressed by Participant 7:

Everybody reacts a bit differently, some people that were more tech savvy jump at the chance to be involved at home, members we hadn't seen involved in the Clubhouse for a while came out of the woodwork to be involved with Zoom, Slack, because it fit really well for them. The people that were not tech savvy, it hit them a lot harder and it was a lot harder to stay connected to them.

\section{Reopening Challenges}

Participants discussed challenges with re-opening the Clubhouse and following guidelines put forth by various public health organizations. These guidelines required social distancing, safety protocols, and limited number of members onsite. These barriers led to prioritizing members who were having the most challenges, limiting the time members can stay at the Clubhouse, and maintaining physical distance during side by side work. These changes are all shifts from the usual Clubhouse standards and practices, that strives for equal opportunity in participation. Participant 12 elaborates on some of these challenges:

Just how the Clubhouse is organized now is different and I am more worried about following the model now than when we were closed. For example, the "side by side work" and having to maintain a 6 feet distance and not having as many people in different areas of the building. I think we are going to have a harder time sticking with the model now than when we were doing the virtual stuff.

Many of the new safety requirements limited the time members could spend in the Clubhouse and required them to book appointments in order to come into the Clubhouse, which is a shift from the previous standards of members being able to come into the Clubhouse anytime. Participant 16 discusses the impact of some of these new guidelines:

Now that we are reopened, we have to go with guidelines of public health and safety, and we are only allowed so many members and normally everything is totally open, and everyone is working together. Some members that would come every day, and stay all day, only get mornings which is really hard to explain and for members to accept.

Another challenge with respect to reopening included prioritizing who is allowed to come into the Clubhouse first. This was often the members that were in higher levels of distress and was a significant shift from the usual standards of equal participation.

\section{Theme 4: Forever Changed}

The final theme discusses the permanency of the adaptations and innovations that have been made by Clubhouse during the pandemic. The changes that have been made have left a permanent mark on all Clubhouses, as it is unclear as to whether Clubhouses will be able to exist as they once did. Many Clubhouses reported that these changes would be permanent even as Clubhouses began to reopen, as a new and innovative way to engage members who cannot come into the Clubhouse. This is expressed by Participant 7:

I don't think Zoom is going away permanently. It is going to be a long time for people that are vulnerable, they probably won't be able to come out until stage 3, which won't be until a vaccination, so we will want to keep the Zoom meetings at least for the rest of the year. I think they will become a part of the new norm because if people can't make it to Clubhouse they can attend and be involved from home.

Other participants reported that adapting the existing programming resulted in better programming and higher levels of engagement. This meant that these new changes could be maintained in the future to create better programming. Participant $11 \mathrm{a}$ and participant $11 \mathrm{~b}$ elaborate on this:

We're seeing members getting involved in things they typically wouldn't, or meeting people they wouldn't have before. We are a pretty big Clubhouse, that means there could be a lot of people that you don't get to meet. So, I think that part has been an added bonus. So, I think when we do open back up, those people might stay connected with those who they met online and stay connected with activities they took part in. 
All Clubhouses discussed maintaining the new programming that has been developed even after Clubhouses are fully operational. Ultimately, maintaining remote programming will allow Clubhouses to engage more members and has created a permanent change in the way the Clubhouse operates. Upon reflecting this theme to the Clubhouses, they noted that COVID-19 has been a "silver lining" in that they have been forced to push forward and innovate the way they interact with members.

\section{Discussion}

The purpose of the present qualitative study was to synthesize the experiences of five Clubhouses in Canada during COVID-19, including the needs of members and the adaptations put in place by the Clubhouses. The results provide insight into how Clubhouses continued to support members during COVID-19, despite not being able to access services in person at each Clubhouse location. These results are particularly important due to the elevated mental health concerns that individuals with mental health problems have exhibited in response to the COVID-19 pandemic.

The results of the study indicated that members reported a number of challenges during the pandemic, including increased mental health symptoms and feelings of loneliness, as well as difficulty accessing mental health services. Research has indicated that mental health concerns in Canada have risen significantly due to the COVID-19 pandemic, while access to services has decreased due to many services closing their doors (Martin and Cooper 2020). Participants noted that often their Clubhouse was the only service provider that was still offering any kind of programming, which speaks to the importance of Clubhouses during this time.

Clubhouses were able to fill gaps in mental health service provision and were also able to meet the needs of members in a number of other areas. For example, many Clubhouses noted that food banks in their communities had shut down, which led to the Clubhouses stepping in to fill this role. The importance of this resource is underscored by recent research on financial stability during COVID-19, with one study suggesting that not being able to afford to prepare during the pandemic, for example, by stockpiling food or being able to afford emergency purchases, leads to increases in mental health symptoms (Yao et al. 2020). The present study highlights how Clubhouses provided an important service to a large group of Canadians with mental health concerns that would otherwise not have their mental health or functional needs met by other services.

Clubhouses have always played a key role in supporting relationship building. This was particularly true during the
COVID-19 pandemic as many members reported feelings of loneliness and isolation. However, Clubhouses were able to bridge these feelings through online programming and services, highlighting the effectiveness of creating social connection through the internet. A review by AlvarezJimenez et al. (2014) found similar results, reporting that internet-based support can create social connectedness, which in turn improves socialization as well as psychotic symptoms and depression. Similarly, Berry et al. (2017) found that individuals who used the social media platform Twitter to discuss mental health issues allowed them to feel a sense of belonging as well as mitigate feelings of loneliness. Clubhouses online programming effectively combated the mental health issues that arose as a result of COVID-19 to foster community, connection and combat feelings of isolation that members discussed. However, it is important to note that while technology has tremendous potential for improving social connection among those with mental health concerns, it is not a complete replacement for in person programming. Some members reported that they were eager to go back to the Clubhouse and preferred the in-house programming over the online platforms. Ultimately, both technology and in person programming play essential roles in allowing Clubhouse members to create social support networks, feel a sense of belonging, and decrease mental health concerns.

\section{Limitations}

Despite the numerous strengths of the present study, limitations exist. First, it is unclear whether the results of this study are generalizable to Clubhouses in other parts of the world, or Clubhouses that are not accredited. It is possible that the difficulties faced by Canadian Clubhouses are different from what are being experienced by other Clubhouses who may have even more difficulty accessing food security, social services, and technology. Further, in the context of the pandemic, it is possible that potential participants did not have the capacity to participate in the present study, therefore missing especially vulnerable individuals in our sample. Further, data was not collected regarding specific psychiatric diagnoses of members and how these diagnoses were impacted during COVID-19. This is important information to be captured, particularly by quantitative data, to understand how mental health symptoms changed over time and whether Clubhouse participation mitigated mental health symptom worsening. Despite these limitations, the results of the study are the first to provide insight into how Clubhouses have supported their members during the COVID-19 pandemic and will assist others in navigating challenges as they arise. 


\section{Implications}

The present study highlights how Clubhouses in Canada were able to adapt quickly in order to meet the needs of their members. The adaptations that were put into place were developed with the Clubhouse Standards as a guide, leading to successful implementation due to the adaptations aligning with the organization's values. Importantly, other organizations that have a collaborative, recovery-oriented approach may benefit from the approach that was taken by Clubhouses. Participants noted the theme that Clubhouse is forever changed; however, it is evident that as long as Clubhouses are guided by the recovery-oriented standards that inform their work, members will have their needs met.

Funding No funding was received for conducting this study.

\section{Compliance with Ethical Standards}

Conflict of interest The authors have no conflicts of interest to declare that are relevant to the content of this article.

Ethical Approval Approval was obtained from the Health Research Ethics Board of Alberta. The procedures used in this study adhere to the tenets of the Declaration of Helsinki.

Consent to Participate Informed consent was obtained from all individual participants included in the study.

\section{References}

Alvarez-Jimenez, M., Alcazar-Corcoles, M. A., González-Blanch, C., Bendall, S., McGorry, P. D., \& Gleeson, J. F. (2014). Online, social media and mobile technologies for psychosis treatment: A systematic review on novel user-led interventions. Schizophrenia Research, 156(1), 96-106. https://doi.org/10.1016/j.schres.2014. 03.02 .

Berry, N., Lobban, F., Belousov, M., Emsley, R., Nenadic, G., \& Bucci, S. (2017). WhyWeTweetMH: Understanding why people use twitter to discuss mental health problems. Journal of Medical Internet Research, 19(4), e107. https://doi.org/10.2196/jmir. 6173.

Biegel, D. E., Pernice-Duca, F., Chang, C., \& D’Angelo, L. (2013). Correlates of peer support in a clubhouse setting. Community Mental Health Journal, 49(3), 249-259. https://doi.org/10.1007/ s10597-012-9502-5.

Braun, V., \& Clarke, V. (2006). Using thematic analysis in psychology. Qualitative Research in Psychology, 3(2), 77-101.

Corrigan, P. W., \& Phelan, S. M. (2004). Social support and recovery in people with serious mental illnesses. Community Mental Health Journal, 40(6), 513-523. https://doi.org/10.1007/s10597004-6125-5.
Gold, P. B., Macias, C., Macias, C., \& Rodican, C. F. (2016). Does competitive work improve quality of life for adults with severe mental illness? Evidence from a randomized trial of supported employment. The Journal of Behavioral Health Services \& Research, 43(2), 155-171. https://doi.org/10.1007/s11414-0149392-0.

Harvey, G., \& Kitson, A. (2016). PARIHS revisited: From heuristic to integrated framework for the successful implementation of knowledge into practice. Implementation Science: IS, 11, 33. https://doi.org/10.1186/s13012-016-0398-2.

ICCD. (2015). Supporting mental health awareness. Retrieved September 10, 2020, from https://clubhouse-intl.org/

Jung, S. H., \& Kim, H. J. (2012). Perceived stigma and quality of life of individuals diagnosed with schizophrenia and receiving psychiatric rehabilitation services: A comparison between the clubhouse model and a rehabilitation skills training model in South Korea. Psychiatric Rehabilitation Journal, 35(6), 460-465. https://doi.org/10.1037/h0094580.

Kozloff, N., Mulsant, B. H., Stergiopoulos, V., \& Voineskos, A. N. (2020). The COVID-19 global pandemic: Implications for people with schizophrenia and related disorders. Schizophrenia Bulletin, 46(4), 752-757. https://doi.org/10.1093/schbul/ sbaa051.

Martin, L., \& Cooper, M. (2020). Mental health during COVID-19 outbreak wave 1. Mental Health Research Canada \& Pollara Strategic Insights. 2020: Retrieved July 30, 2020, from https:// www.mhrc.ca/wp-content/uploads/2020/05/Full-Report-of-Find ings-of-Survey-FINAL.pdf

McKay, C., Nugent, K. L., Johnsen, M., Eaton, W. W., \& Lidz, C. W. (2018). A systematic review of evidence for the clubhouse model of psychosocial rehabilitation. Administration and Policy in Mental Health and Mental Health Services Research, 45(1), 28-47. https://doi.org/10.1007/s10488-016-0760-3.

Mental Health Commission of Canada. (2020). COVID-19 and mental health: Policy responses and emerging issues [Environmental scan]. Ottawa, Canada. Retrieved July 30, 2020, from https:// www.mentalhealthcommission.ca/sites/default/files/2020-06/ COVID_19_policy_responses_emerging_issues_eng.pdf.

Mutschler, C., Rouse, J., McShane, K., \& Habal-Brosek, C. (2018). Developing a realist theory of psychosocial rehabilitation: The clubhouse model. BMC Health Services Research, 18(1), 442-512. https://doi.org/10.1186/s12913-018-3265-9.

Raeburn, T., Halcomb, E., Walter, G., \& Cleary, M. (2013). An overview of the clubhouse model of psychiatric rehabilitation. Australasian Psychiatry, 21(4), 376-378.

Schonebaum, A. D., Boyd, J. K., \& Dudek, K. J. (2006). A comparison of competitive employment outcomes for the clubhouse and PACT models. Psychiatric Services, 57(10), 1416-1420. https://doi.org/10.1176/ps.2006.57.10.1416.

Tsang, A. W., Ng, R. M., \& Yip, K. (2010). A six-month prospective case-controlled study of the effects of the clubhouse rehabilitation model on chinese patients with chronic schizophrenia. East Asian Archives of Psychiatry, 20(1), 23-30.

Yao, H., Chen, J. H., \& Xu, Y. F. (2020). Patients with mental health disorders in the COVID-19 epidemic. The Lancet Psychiatry, 7(4), e21.

Publisher's Note Springer Nature remains neutral with regard to jurisdictional claims in published maps and institutional affiliations. 